\title{
Trauma Surgery $\&$ Acute Care Open \\ COVID-19 and trauma: how social distancing orders altered the patient population using trauma services during the 2020 pandemic
}

\author{
Casey E Pelzl (D , ${ }^{1}$ Kristin Salottolo, ${ }^{1}$ Kaysie Banton, ${ }^{2}$ Robert M Madayag, ${ }^{3}$ \\ David Hamilton, ${ }^{4}$ Therese M Duane, ${ }^{5}$ Matthew Carrick, ${ }^{5}$ Mark Lieser, ${ }^{6}$ Gina Berg, ${ }^{7}$ \\ David Bar-Or 1,8
}

'ION Research, Englewood, Colorado, USA

${ }^{2}$ Department of Trauma Surgery, Swedish Medical Center, Englewood, Colorado, USA ${ }^{3}$ Trauma Services Department, St Anthony Hospital \& Medical Campus, Lakewood, Colorado, USA

${ }^{4}$ Trauma Services Department, Penrose-St Francis Health Services, Colorado Springs, Colorado, USA

${ }^{5}$ Trauma Services Department, Medical Center of Plano, Plano, Texas, USA

${ }^{6}$ Department of Trauma Services, Research Medical Center, Kansas City, Missouri, USA ${ }^{7}$ Department of Trauma Services, Wesley Medical Center, Wichita, Kansas, USA

${ }^{8}$ Department of Trauma Research, Swedish Medical Center, Englewood, Colorado, USA

Correspondence to Dr David Bar-Or; davidbme49@ gmail.com

Received 17 November 2020 Revised 5 January 2021 Accepted 29 January 202

(c) Author(s) (or their employer(s)) 2021. Re-use permitted under CC BY-NC. No commercial re-use. See rights and permissions. Published by BMJ.

\section{To cite: Pelzl CE,}

Salottolo K, Banton K, et al.

Trauma Surg Acute Care Open 2021:6:e000645.

\section{ABSTRACT}

Background Recent studies have reported changes in trauma volumes resulting from the COVID-19 pandemic and social distancing orders (SDOs) implemented by federal and state governments. However, literature is lacking on demographic, injury and outcome patterns. Methods This retrospective, cross-sectional study included patients aged $\geq 18$ years at six US level 1 trauma centers. Patients not discharged by the date of data acquisition were excluded. Demographic, injury and outcome variables were assessed across four time periods: period 1 (January 1, 2019-December 31, 2019); period 1b (March 16, 2019-June 30, 2019); period 2 (January 1, 2020-March 15, 2020); and period 3 (March $16,2020-J u n e \quad 30,2020)$. Patients admitted in period 3 were compared with patients presenting during all other periods. Categorical data were compared with $\chi^{2}$ and Fisher's exact tests, and continuous data were assessed with Student's t-tests and Wilcoxon rank-sum tests. Results We identified 18567 patients: 12797 patients in period 1 (including 3707 in period 1b), 2488 in period 2 and 3282 in period 3. Compared with period 1, period 3 had a statistically significant decrease in mean patient volume, increase in portion of penetrating injuries, increase in higher levels of trauma activation, change in emergency department discharge disposition locations, increase in in-hospital mortality and a shorter hospital length of stay. Comparison between period $1 \mathrm{~b}$ and period 3 demonstrated a decrease in mean patient volume, increase in penetrating injuries, increase in high acuity trauma activations and increase in in-hospital mortality rate. From period 2 to period 3 , the penetrating injuries rose from $6.7 \%$ to $9.4 \%$ $(p=0.004)$, injury severity scale $\geq 25$ increased from $5.9 \%$ to $7.7 \%$ ( $\mathrm{p}=0.002$ ), full trauma team activations increased from $13.7 \%$ to $16.4 \%(p<0.001)$, interhospital transfers decreased from $36.7 \%$ to $31.6 \%(p<0.001)$ and the in-hospital mortality rate increased from $3.3 \%$ to $4.2 \%$ $(p=0.003)$.

Discussion Beyond altering social interactions among people, the federal SDO is associated with changes in trauma volumes, demographics and injury patterns among patients seeking care at six level 1 hospitals during the pandemic.

Level of evidence IV, prognostic and epidemiological.

\section{BACKGROUND}

On March 16, 2020, faced with rapid nationwide spread of COVID-19, the White House implemented a social distancing order (SDO) in an effort to slow the spread of the highly virulent SARS-CoV-2. ${ }^{1}$ The order was expected to remain in place for 15 days, but this short period was insufficient to stem the drastic rise in infections, and the order was eventually extended. After this federal order, states began executing their own 'stay-athome' or 'shelter-in-place' orders. Although these directives were intended to stem the spread of COVID-19 infections, these directives for physical isolation had effects beyond preventing disease spread.

With the vast majority of US citizens remaining at home, the trauma patient population shifted. The weekly number of emergency department (ED) visits in the USA dropped precipitously during the early weeks of the pandemic. The National Syndromic Surveillance Program reported that mean ED visits were down to 1.2 million per week in 2020 (March 29-April 25) from 2.1 million per week during a similar time period in 2019 (March 31-April 27). ${ }^{2}$ Other countries also reported similar decreases in the numbers of people seeking care in the ED. ${ }^{3-6}$ While many of these 'missing' patients were choosing to use virtual doctor visits and other forms of telemedicine, other patients were avoiding the healthcare system altogether, even when their medical situations were life threatening. ${ }^{3-9}$

There remains a dearth of knowledge on how governmentally imposed lockdowns changed the demographics, clinical characteristics and outcomes of injured patients acutely presenting to the hospital. This study examined how the COVID-19 pandemic and the resulting federal SDO affected the numbers and types of patients presenting with traumatic injury to six US level 1 trauma hospitals.

The primary aim of this study is to describe and compare injured patients across several different demographic, injury and outcome variables through different time periods defined by the incident pandemic and SDO. The findings presented herein will help clinicians and hospital administrators elucidate the ways in which the pandemic changed the scenery of traumatic injuries and hospitalizations in this country in the wake of the federal government's call for social distancing.

\section{METHODS}

Patients were identified from the trauma registries at six hospitals across Colorado, Kansas, Missouri 
and Texas from January 1, 2019 to June 30, 2020. Patients who had not yet been discharged from the hospital at the time of data acquisition from the trauma registry were excluded. All variables used in these analyses were obtained from the trauma registries; no patient charts were accessed.

The primary independent variable was time period. Based on admission date, patients were categorized into one of four time periods, in relation to the pandemic itself as well as the institution of the federal SDO: period 1 (pre-COVID-19: January 1, 2019-December 31, 2019); period 1b (pre-COVID-19, comparable time period: March 16, 2019-June 30, 2019); period 2 (COVID-19 pre-SDO: January 1，2020-March 15，2020); period 3 (COVID-19 post-SDO: March 16, 2020-June 30, 2020). Period $1 \mathrm{~b}$ was examined to control for potential seasonality of injuries.

Dependent variables of interest included patient volume, patients per day, age, sex, race, injury type, injury severity scale (ISS) score, level of trauma activation, interhospital transfer status, ED discharge disposition, in-hospital mortality, hospital length of stay (HLOS) and intensive care unit LOS. All variables were measured or counted in aggregate across all six participating level 1 trauma centers.

Categorical data were described as proportions (n) of the total population during the time period. Comparisons among categorical data were assessed with $\chi^{2}$ and Fisher's exact tests, where applicable. Continuous data (ie, patients per day and lengths of stay measures) were described as means and SD or medians and IQR for non-normally distributed data. Comparisons among continuous data were assessed with Student's t-tests or Wilcoxon rank-sum tests.

The following comparisons were analyzed for differences preSDO and post-SDO: period 1 versus period 3; period $1 \mathrm{~b}$ versus period 3; and period 2 versus period 3. Demographic, injury or outcome variables found to be statistically significantly different between the two pandemic time periods (periods 2 and 3) were graphically presented to understand the week-to-week changes during the course of the COVID-19 pandemic in the first half of 2020 .

The alpha level for this study was 0.01 due to the large population size. All statistical analyses were generated using SAS software V.14.3 (2016, SAS Institute Inc, Cary, NC, USA).

\section{RESULTS}

Across six level 1 trauma centers, we identified 18567 patients from January 1, 2019 to June 30, 2020. Of these, 12797 presented to the six hospital EDs during period 1; 3707 presented during period $1 \mathrm{~b} ; 2488$ presented during period 2; and 3282 presented during period 3 .

Changes in the overall patient volume during the study period are presented in figure 1 . The aggregate patients per day across all six hospitals saw a slight incline into the summer of 2019 and a subsequent decline during the second half of 2019, which continued into the first quarter of 2020. On March 16, 2020, the date of implementation of the federal SDO, the graph shows a significant drop-off in numbers of patients per day, which remains steady for about a month and then gradually rises through the end of the study period.

The six level 1 hospitals saw a statistically significant decrease in mean number of patients per day from period 3 (30.7, SD: 8.4) to period 1 (35.1, SD: 6.8, $\mathrm{p}<0.0001)$ and period $1 \mathrm{~b}(34.6$, $\mathrm{SD}: 6.8, \mathrm{p}<0.001)$. During the pandemic, however, from period 2 (33.2, SD: 7.0$)$ to period 3, there was no significant change in patients per day $(\mathrm{p}=0.035)$.

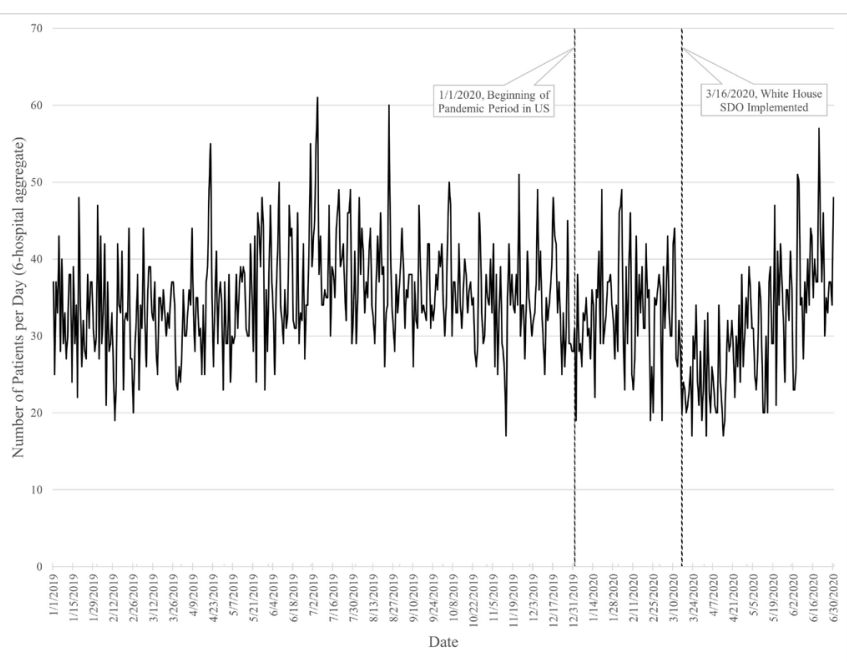

Figure 1 Patients per day presenting to six US level 1 trauma hospitals before and during the COVID-19 pandemic. SDO, social distancing order.

Comparisons before and during the COVID-19 pandemic: periods 1 and $1 \mathrm{~b}$ versus period 3

When comparing all of 2019 (period 1) to the post-SDO era in 2020 (period 3), there were statistically significant differences in injury type, level of trauma team activation, ED discharge disposition, in-hospital mortality and HLOS (table 1). Compared with period 1, a larger portion of patients in period 3 had a penetrating injury $(9.4 \%$ vs $6.9 \%, p<0.0001)$. The levels of trauma team activation changed significantly from period 1 to period 3 , with a shift toward a larger percentage of full activations and consults in period $3(\mathrm{p}<0.0001)$. Patients' ED dispositions were statistically significantly different from period 1 to period 3 as well $(p<0.01)$. A greater proportion of patients died in the hospital during period $3(4.2 \%)$ compared with period 1 (3.3\%, $\mathrm{p}<0.0001)$, and patients had a shorter median HLOS during period $3(3.0$, IQR: $1.0-5.0)$ than they did in period 1 (3.0, IQR: 1.6-6.0, $\mathrm{p}<0.0001)$.

When examining comparable lengths of time in 2019 and 2020 (period 1b vs period 3), we identified similar patient demographics but statistically significant differences in injury type, level of trauma team activation and in-hospital mortality rate (table 1 ). Compared with period $1 \mathrm{~b}$, the proportion trauma activation levels were again significantly different in period 3 $(\mathrm{p}<0.0001)$, the percentage of penetrating injuries rose $(7.3 \% \mathrm{vs}$ $9.4 \%, \mathrm{p}<0.01)$ and the in-hospital mortality rate increased from $3.2 \%$ to $4.2 \%(\mathrm{p}<0.001)$.

Changes during the pandemic: pre-SDO period 2 versus postSDO period 3

Between the pandemic periods, pre-SDO period 2 and post-SDO period 3, there were significant differences in the rates of elderly $(\geq 65)$ patients presenting to the hospital as well the injury types seen, the severity of injuries, the level of trauma team activation, interfacility transfers and the rate of in-hospital mortality. The proportion of elderly trauma patients presenting to the ED decreased significantly from period 2 to period $3(44.8 \%$ vs $40.9 \%, \mathrm{p}<0.01$ ); this was the only demographic variable that exhibited a difference. Similar to the previous time period comparisons, there was a significant difference in penetrating injuries from period 2 to period $3(6.7 \%$ vs $9.4 \%, \mathrm{p}<0.01)$; however, not found in previous comparisons was the increase 
Table 1 Comparisons of patients presenting to six level 1 trauma hospitals during various prepandemic (2019) and midpandemic (2020) time periods

\begin{tabular}{|c|c|c|c|c|}
\hline Time period & Period 1 & Period $1 \mathrm{~b}$ & Period 2 & Period 3 \\
\hline Year & 2019 & 2019 & 2020 & 2020 \\
\hline Dates & January 1-December 31 & March 16-June 30 & January 1-March 15 & March 16-June 30 \\
\hline Total patients & 12797 & 3707 & 2488 & 3282 \\
\hline Average patients per day across all six sites & $35.1(6.8)^{* * *}$ & $34.6(6.8)^{* *}$ & $33.2(7.0)$ & $30.7(8.4)$ \\
\hline Age $\geq 65$ years, $\%(n)$ & $42.9(5496)$ & $41.4(1536)$ & $44.8(1114)^{*}$ & $40.9(1341)$ \\
\hline Female, \% (n) & $42.9(5487)$ & $41.9(1553)$ & $44.4(1104)$ & $41.2(1351)$ \\
\hline \multicolumn{5}{|l|}{ Race, \% (n) } \\
\hline White & 76.5 (9796) & $75.6(2803)$ & $76.2(1895)$ & $74.8(2454)$ \\
\hline Black & $10.1(1287)$ & $10.5(390)$ & $9.5(237)$ & $10.4(342)$ \\
\hline Asian & $1.6(202)$ & $1.5(56)$ & $1.7(41)$ & $1.6(53)$ \\
\hline American Indian & $0.7(88)$ & $0.7(27)$ & $1.0(25)$ & $0.8(27)$ \\
\hline Native Hawaiian & $1.0(131)$ & $1.1(39)$ & $1.4(35)$ & $1.7(55)$ \\
\hline Other/unknown/undocumented & $10.1(1293)$ & $10.6(392)$ & $10.3(255)$ & $10.7(351)$ \\
\hline Injury type, \% (n) & $* * *$ & * & * & \\
\hline Blunt & $89.6(11461)$ & 89.4 (3 314) & 89.7 (2 232) & $87.1(2,857)$ \\
\hline Penetrating & $6.9(884)$ & $7.3(269)$ & $6.7(168)$ & $9.4(308)$ \\
\hline Other/undocumented & $3.5(452)$ & 3.4 (124) & $3.5(88)$ & $3.6(117)$ \\
\hline Injury severity, \% (n) & & & * & \\
\hline ISS $\leq 15$ & $83.1(10637)$ & $82.5(3057)$ & $85.2(2119)$ & $81.8(2685)$ \\
\hline ISS 16-24 & $9.8(1253)$ & $10.5(391)$ & $9.0(223)$ & $10.5(343)$ \\
\hline ISS $\geq 25$ & $7.1(907)$ & $7.0(259)$ & $5.9(146)$ & $7.7(254)$ \\
\hline Level of trauma team activation, $\%$ (n) & $* * *$ & $* * *$ & $* * *$ & \\
\hline Full/requires immediate response & $15.1(1936)$ & $16.1(597)$ & $13.7(340)$ & $16.4(538)$ \\
\hline Partial/requires non-immediate response & $29.3(3746)$ & $31.0(1149)$ & $26.3(655)$ & $27.9(915)$ \\
\hline Consult/requires eventual response & $8.3(1064)$ & $8.1(301)$ & $16.2(404)$ & $18.3(600)$ \\
\hline None/no trauma surgeon required & $34.9(4460)$ & $32.3(1197)$ & $30.9(769)$ & $24.8(814)$ \\
\hline Other/unlisted & $12.4(1591)$ & $12.5(463)$ & $12.9(320)$ & $12.6(415)$ \\
\hline Interhospital transfers, \% (n) & $33.3(4258)$ & $33.3(1236)$ & $36.7(912)^{* * *}$ & $31.6(1036)$ \\
\hline ED discharge disposition, \% (n) & * & & & \\
\hline Died & $0.5(69)$ & $0.5(18)$ & $0.4(10)$ & $0.7(24)$ \\
\hline ICU & $24.9(3180)$ & 25.9 (959) & 24.1 (599) & $24.0(787)$ \\
\hline OR/IR & $8.1(1033)$ & $8.9(330)$ & $7.8(193)$ & $9.2(303)$ \\
\hline Floor/stepdown/observation & $52.1(6671)$ & 49.9 (1849) & $53.9(1341)$ & $52.2(1714)$ \\
\hline Left hospital (transfer/home) & $10.1(1292)$ & 10.8 (399) & $10.0(248)$ & $10.8(355)$ \\
\hline Other/undocumented & $4.3(552)$ & $4.1(152)$ & $3.9(97)$ & $3.0(99)$ \\
\hline In-hospital mortality, \% (n) & $3.3(421)^{* * *}$ & $3.2(119)^{* *}$ & $3.3(82)^{*}$ & $4.2(137)$ \\
\hline HLOS, median (IQR), days & $3.0(1.6-6.0)^{* * *}$ & $3.0(1.0-5.9)$ & $3.0(1.7-6.0)$ & $3.0(1.0-5.0)$ \\
\hline ICULOS, median (IQR), days & $0.0(0.0-2.0)$ & $0.0(0.0-2.0)$ & $0.0(0.0-2.0)$ & $0.0(0.0-2.0)$ \\
\hline
\end{tabular}

Level of statistically significant difference from period $3:{ }^{*} p<0.01 ;{ }^{* *} p<0.001 ;{ }^{* * *} p<0.0001$. Combining percents may not equal $100 \%$ due to rounding.

d, days; ED, emergency department; HLOS, hospital length of stay; ICULOS, intensive care unit length of stay; IR, interventional radiology; ISS, injury severity scale; OR, operating room.

in proportion of injuries with ISS $\geq 25(5.9 \%$ vs $7.7 \%, \mathrm{p}<0.01)$ that was observed from period 2 to period 3. Again, there was a difference from period 2 to period 3 in the proportions of trauma team activation levels, with full (13.7\% vs $16.4 \%)$, partial $(26.3 \%$ vs $27.9 \%)$ and consult $(16.2 \%$ vs $18.3 \%)$ activations all rising $(\mathrm{p}<0.0001)$. Finally, rates of in-hospital mortality increased from $3.3 \%$ in period 2 to $4.2 \%$ in period 3 ( $p<0.01$ ), a $27.3 \%$ increase in death rate.

When examining the weekly changes among these variables found to be statistically significantly different between periods 2 and 3 , the proportion of elderly trauma patients presenting to the hospitals reached a peak during the week of the White
House SDO, and then dropped continuously through period 3 (figure 2). The proportions of blunt and penetrating injuries exhibit similar up-and-down patterns through period 2, until there was an inflection around week 13 (March 22, 2020-March 28, 2020), just after the SDO implementation, at which point there is a precipitous drop in the share of blunt injuries, accompanied by a concomitant rise in the portion of penetrating injuries (figure 3 ). The percentage of patients with a mild injury (ISS $\leq 15$ ) remained fairly consistent through the pandemic periods, except for a notable dip just after the SDO was implemented, at which point injuries with ISS $>15$ peaked (figure 4). After this post-SDO peak in higher ISS scores, the proportion of ISS 


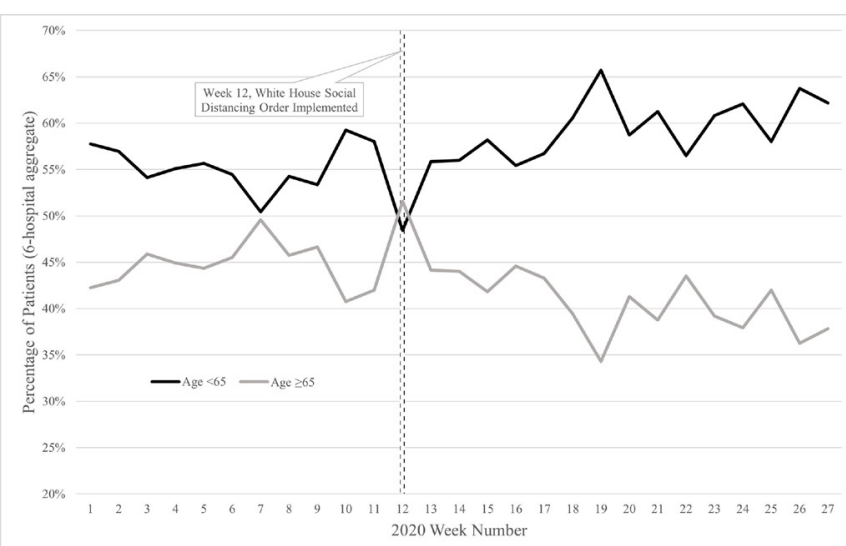

Figure 2 Changes in weekly proportions of age strata among patients presenting to six US level 1 trauma hospitals during the COVID-19 pandemic of 2020.

scores 16-24 remained fairly constant and the of ISS scores $>25$ declined through period 3 .

Rates of trauma team activation levels varied consistently across the first 6 months of 2020 (figure 5). The portion of full/ partial activations decreased through week 8 (period 2, February $16,2020-F e b r u a r y 22,2020)$ of the pandemic and then reached a peak during week 15 (period 3, April 5, 2020-April 11, 2020), when they exceeded other levels of trauma activations for that one and only week during the pandemic. The rate of interhospital transfer patients exhibited consistent fluctuation through week 10 (March 1, 2020-March 7, 2020) and then dropped significantly into week 12 , when the SDO was implemented (figure 6). The percentage of transfers continued to decline through period 3.

Weekly in-hospital mortality rates rose progressively through period 2, reaching a peak of $9.4 \%$ during the week of the White House SDO and began to rise again in June (figure 7). The lowest in-hospital mortality rate for period 2 was $1.7 \%$ during week 10 (March 1, 2020-March 7, 2020); for period 3, it was $1.8 \%$ during week 18 (April 26, 2020-May 2, 2020). The highest single-day in-hospital mortality rate (19.1\%) during the pandemic was seen on March 20, 2020, less than 1 week after the implementation of the White House SDO.

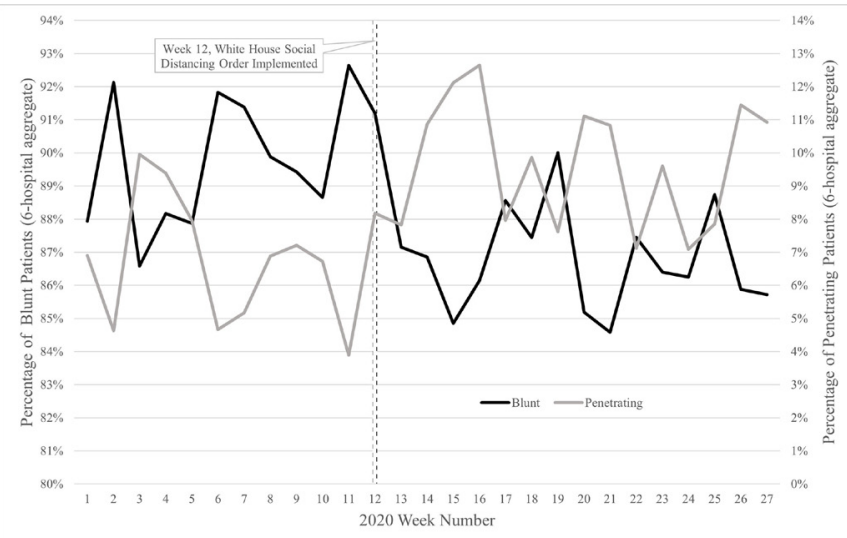

Figure 3 Changes in weekly proportions of injury mechanisms among patients presenting to six U S level 1 trauma hospitals during the COVID-19 pandemic of 2020.

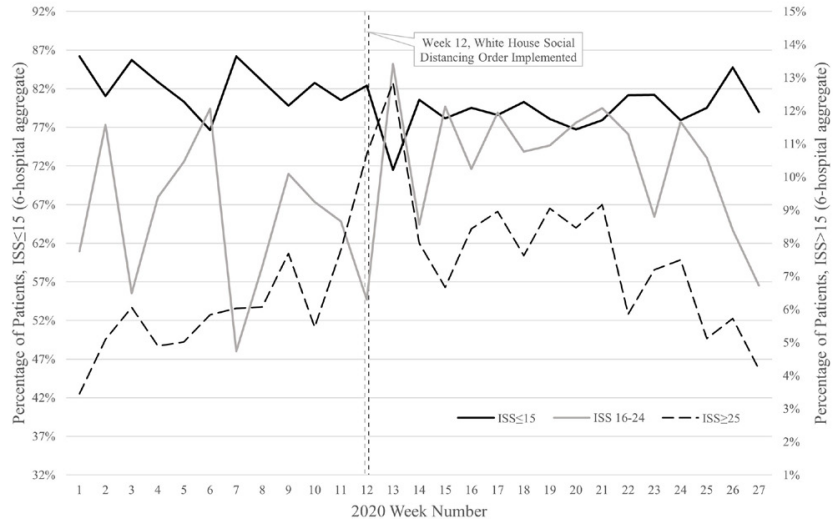

Figure 4 Changes in weekly proportions of ISS score ranges among patients at six US level 1 trauma hospitals during the COVID-19 pandemic of 2020. ISS, injury severity scale.

\section{DISCUSSION}

To properly prepare for inevitable future pandemic, epidemic or local outbreak scenarios, it is vital for hospital administrators and clinicians to understand how the COVID-19 pandemic altered the trauma patient population. Similar to other smaller studies that examined narrower windows of time during the COVID-19 pandemic, the daily volume of trauma patients decreased significantly after the implementation of the White House's SDO. The novelty in our findings was that our participating hospitals experienced an approximate $10 \%$ reduction in patient volumes associated with the pandemic and SDO orders, which was not as drastic a drop as those reported by other publishing centers in and outside the USA $(37.3 \%$ to $57.4 \%) .{ }^{10-13}$ In a time when hospital beds for COVID-19 patients are at a premium, this finding is quite remarkable. Even though medical and surgical service lines were attempting to free up bed space for incoming patients with COVID-19 by canceling elective procedures, limiting medical admissions and discharging existing patients when possible, trauma service lines were faced with more severe injuries during the pandemic, making it necessary to admit patients for critical care interventions. These findings may allow hospitals administrators and staff to plan for changes to the trauma and critical

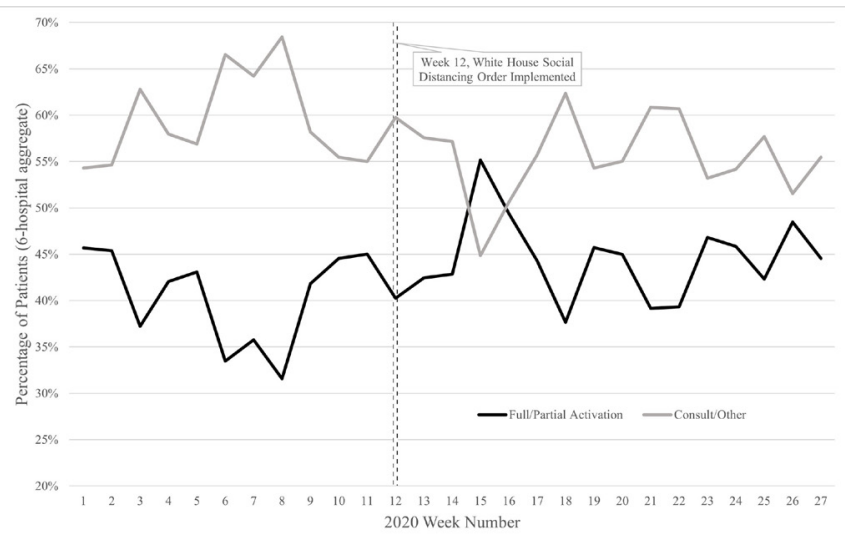

Figure 5 Changes in weekly proportions of trauma activation levels among patients presenting to six US level 1 trauma hospitals during the COVID-19 pandemic of 2020. 


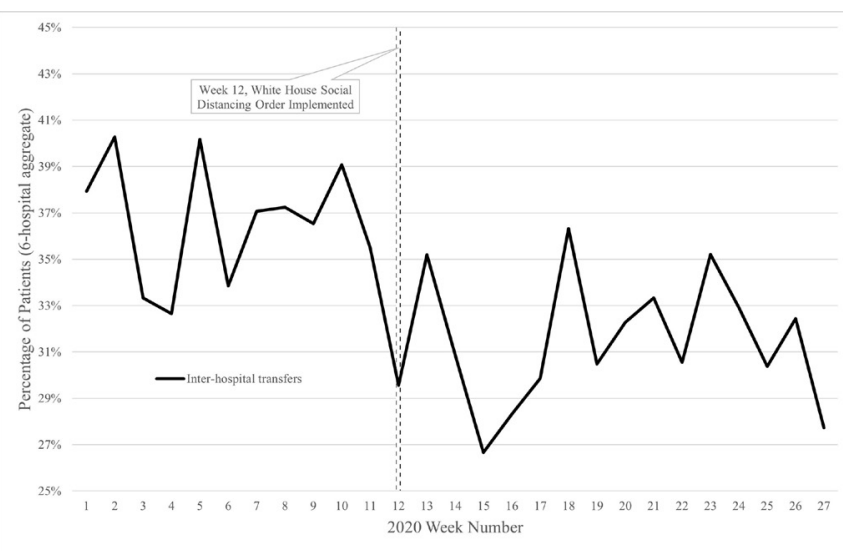

Figure 6 Changes in weekly proportions of interhospital transfer patients presenting to six US level 1 trauma hospitals during the COVID-19 pandemic of 2020.

care system that must be deployed to care for a new and different set of patients, should a second wave or future pandemic occur.

The trauma patients presenting to the six participating hospitals during period 3 had more severe injuries (ie, ISS $\geq 25$ ) than patients in period 2. Increased injury severity is certainly tied to the need for hospital admission, and it changes how the on-call trauma team reacts to the patient's arrival at the hospital. ${ }^{14}$ The shift toward high acuity injuries likely resulted in patients requiring a more critical level of trauma team activation, which was observed in the increase in percentages of full activations from periods $1,1 \mathrm{~b}$ and 2 to period 3 . To our knowledge, this study is the first to examine the change in hospitals' trauma team responses or activation levels during the COVID-19 pandemic.

It is possible that the observed trend toward higher injury severity in period 3 may be a result of 'artificially' increased ISS scores. Predicated on fears of contracting COVID-19 in the hospital, injured patients have delayed their visits to the ED for treatment, leading to more complicated injuries, which are demonstrated in the elevated ISS scores immediately after the federal SDO. ${ }^{15}$ These traumatic injuries that were left untreated during the delay in presentation may have worsened or perhaps wounds became infected, earning the patient a higher ISS than if she had presented immediately to the ED. During the COVID-19 pandemic, hospitals were finding similar issues with medical

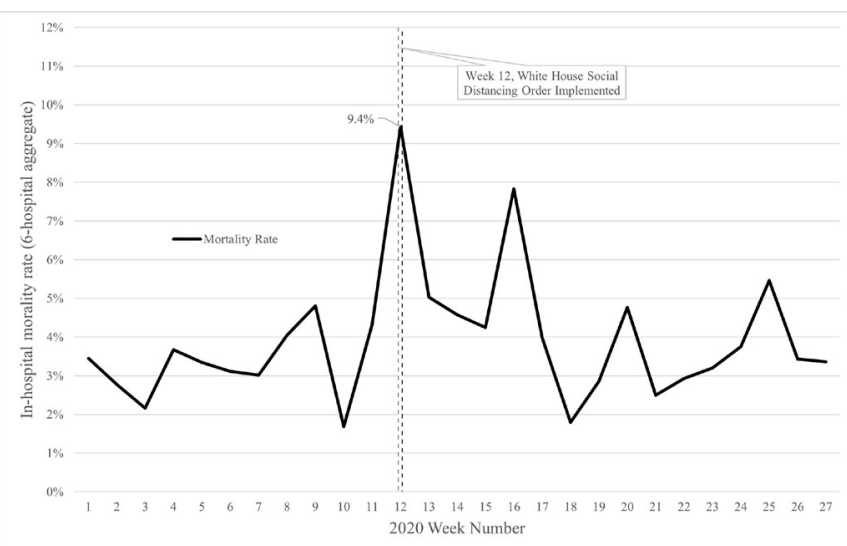

Figure 7 Changes in weekly in-hospital mortality rates at six US level 1 trauma hospitals during the COVID-19 pandemic of 2020. patients avoiding the ED for urgent cardiac care, which put them at significant risk of avoidable morbidity and mortality. ${ }^{8}$ To combat this, hospital systems began issuing statements on their websites, explaining how clinicians and staff were taking all possible precautions to prevent the spread of COVID-19 and imploring patients not to ignore their symptoms and seek medical care immediately. ${ }^{6} 1617$

Another facet affecting traumatic injuries during the pandemic was assault; parts of the USA were seeing a rise in violent personon-person trauma in the early weeks of social distancing. ${ }^{18-20}$ This increase in interperson violence is another unintended effect of national and state SDOs and may be associated with the increase in injury severity as well as the rise in proportion of penetrating injuries observed from all pre-SDO periods $(1,1 \mathrm{~b}$ and 2) to period 3 .

The significant drop in interhospital transfers over the course of the COVID-19 pandemic is another important finding, not reported to our knowledge. The change in interfacility transfers has significant impacts on the overall trauma population. All six hospitals included in this study are level 1 trauma centers and necessarily receive patients that require a higher level of care than could be administered at the originating facility. During period 2 , the proportion of trauma patients that were interhospitals transfers stood at $36.7 \%$; in period 3, it was $31.6 \%$. Although patients often need to travel to other hospitals for higher levels of care, the goal of avoiding COVID-19 spread between hospitals has disrupted the interhospital transfer process. ${ }^{21}$

Although most demographics did not change between the pre-SDO periods and post-SDO period 3, we did identify a decrease in the proportion of hospitalizations of elderly $(\geq 65$ years) patients from period 2 to period 3. The risk of severe COVID-19 infection and related morbidity and mortality in the elderly population has been reiterated across medical, governmental and journalistic publications. ${ }^{22-24}$ Elderly citizens were confronted with constant reminders of the increased risks of COVID-19 infection and death that come with advanced age, along with the fact that risks were even further elevated at an ED or hospital. The reduction in trauma hospitalizations in this section of the population may have stemmed from fears of contracting the COVID-19, but a strict adherence to federal and state SDOs may have reduced participation in injury-causing activities, which could also account for the drop.

In-hospital mortality changed continuously through the COVID-19 pandemic. There was a notable 27.2\% increase in the death rate from period 2 to period 3 and comparable rates of increase from periods 1 and $1 \mathrm{~b}$ to period 3 . It is possible that the rise in-hospital death rate is due to a combination of the aforementioned increase in interpersonal violence, penetrating injuries, injury severity, as well as community-acquired or iatrogenic COVID-19 infections.

Our analysis is inherently limited by its retrospective design. In addition, placing focus on one date (March 16, 2020) as the pivot point for any observed changes in trauma populations presenting to our six level 1 hospitals is a limitation. Most states enacted individual SDOs after the White House-all with varying start and end dates. This likely changed social interactions and altered trauma patterns in a manner specific to each state. However, to provide consistency across all six participating hospitals, we chose one date common to all states. We also excluded children from our study, so we are unable to make any conclusions about pediatric patients who may have suffered significantly more trauma than adults due to significant upticks in household violence and physical abuse. ${ }^{25}$ With regard to in-hospital mortality, we were unable to assess any causes of 
death, so any causal inferences made about increasing death rate must be interpreted with discretion. Furthermore, there are other variables not analyzed herein (eg, patient insurance status, in-hospital procedures and blood products administered) that could have contributed to our understanding of how the trauma population and the outcomes these patients experience changed post-SDO.

\section{CONCLUSION}

The consequences of the federal and state social distancing, 'stay-at-home' and 'shelter-in-place' orders were far-reaching. Beyond changing social interactions among people- oftentimes turning them violent-these orders were also associated with a change in the numbers and injury severities of patients that presented to trauma centers for evaluation and admission. Six level 1 trauma hospitals across the Western and Midwestern USA saw significant decreases in trauma patient visits per day during the COVID-19 pandemic but saw a rise in the proportion of patients with elevated ISS scores. Should a future 'second wave' of COVID-19 infections and strict social distancing situation arise, faculty at level 1 trauma hospitals should be prepared for fewer patients with more severe injuries.

Contributors CEP completed the literature search. All authors assisted in the study design. CEP and KS participated in data collection and data analysis. All authors assisted in data interpretation, manuscript writing and critical revisions.

Funding The authors have not declared a specific grant for this research from any funding agency in the public, commercial or not-for-profit sectors.

Competing interests None declared.

Patient consent for publication Not required.

Ethics approval Institutional Review Board (IRB) approvals along with Health Insurance Portability and Accountability Act (HIPAA) Full Waivers were granted for all six participating institutions. St. Anthony Hospital and Penrose Hospital - Catholic Health IRB Ref. \#1602122-2. Swedish Medical Center and Wesley Medical Center HCA-HealthONE IRB Ref. \#1602124-2. Medical City Plano - Medical City Plano IRB Ref. \#1602123-2. Research Medical Center - Western IRB Ref. \#1-1344386-1.

Provenance and peer review Not commissioned; externally peer reviewed.

Data availability statement Data are available on reasonable request. All data were collected using the trauma registries from six hospitals. These data were analyzed in their deidentified form. Fully identified data are not available in aggregate to anyone, unless they have data access rights at all six participating hospitals.

Open access This is an open access article distributed in accordance with the Creative Commons Attribution Non Commercial (CC BY-NC 4.0) license, which permits others to distribute, remix, adapt, build upon this work non-commercially, and license their derivative works on different terms, provided the original work is properly cited, appropriate credit is given, any changes made indicated, and the use is non-commercial. See: http://creativecommons.org/licenses/by-nc/4.0/.

\section{ORCID iD}

Casey E Pelzl http://orcid.org/0000-0002-0954-9863

\section{REFERENCES}

1 The White House. Coronavirus Guidelines for America. 2020. https://www. whitehouse.gov/briefings-statements/coronavirus-guidelines-america (10 Aug 2020).

2 Hartnett KP, Kite-Powell A, DeVies J, Coletta MA, Boehmer TK, Adjemian J, Gundlapalli AV, National Syndromic Surveillance Program Community of Practice. Impact of the COVID-19 Pandemic on Emergency Department Visits - United States, January 1, 2019-May 30, 2020. MMWR Morb Mortal Wkly Rep 2020;69:699-704.

3 Metzler B, Siostrzonek P, Binder RK, Bauer A, Reinstadler SJ. Decline of acute coronary syndrome admissions in Austria since the outbreak of COVID-19: the pandemic response causes cardiac collateral damage. Eur Heart J 2020;41:1852-3.
4 Tam C-CF, Cheung K-S, Lam S, Wong A, Yung A, Sze M, Lam Y-M, Chan C, Tsang T-C, Tsui M, et al. Impact of coronavirus disease 2019 (COVID-19) outbreak on STsegment-elevation myocardial infarction care in Hong Kong, China. Circ Cardiovasc Qual Outcomes 2020;13:e006631.

5 Lazzerini M, Barbi E, Apicella A, Marchetti F, Cardinale F, Trobia G. Delayed access or provision of care in Italy resulting from fear of COVID-19. Lancet Child Adolesc Health 2020;4:e10-11.

6 Wong LE, Hawkins JE, Langness S, Murrell KL, ris P, Sammann A. Where are all the patients? Addressing Covid-19 fear to encourage sick patients to seek emergency care. NEJM Catalyst Innov Care Delivery 2020.

7 Garcia S, Albaghdadi MS, Meraj PM, Schmidt C, Garberich R, Jaffer FA, Dixon S, Rade JJ, Tannenbaum M, Chambers J, et al. Reduction in ST-segment elevation cardiac catheterization laboratory activations in the United States during COVID-19 pandemic. J Am Coll Cardiol 2020;75:2871-2.

8 Rosenbaum L. The Untold Toll - The Pandemic's Effects on Patients without Covid-19. N Engl J Med 2020;382:2368-71.

9 Siow MY, Walker JT, Britt E, Kozy JP, Zanzucchi A, Girard PJ, Schwartz AK, Kent WT. What was the change in telehealth usage and proportion of No-show visits for an orthopaedic trauma clinic during the COVID-19 pandemic? Clin Orthop Relat Res 2020:478:2257-63.

10 Mitchell RD, O'Reilly GM, Mitra B, Smit DV, Miller J-P, Cameron PA. Impact of COVID-19 state of emergency restrictions on presentations to two Victorian emergency departments. Emerg Med Australas 2020;32:1027-33.

11 Kamine TH, Rembisz A, Barron RJ, Baldwin C, Kromer M. Decrease in trauma admissions with COVID-19 pandemic. West J Emerg Med 2020;21:819-22.

12 Stoker S, McDaniel D, Crean T, Maddox J, Jawanda G, Krentz N, Best J, Speicher M, Siwiec R. Effect of Shelter-in-Place orders and the COVID-19 pandemic on orthopaedic trauma at a community level II trauma center. J Orthop Trauma 2020;34:e336-42.

13 Leichtle SW, Rodas EB, Procter L, Bennett J, Schrader R, Aboutanos MB. The influence of a statewide "Stay-at-Home" order on trauma volume and patterns at a level 1 trauma center in the united states. Injury 2020;51:2437-41.

14 American College of Surgeons Committee on Trauma. Resources for Optimal Care of the Injured Patient. https://www.facs.org/-/media/files/quality-programs/trauma/vrcresources/resources-for-optimal-care.ashx (9 Oct 2020).

15 Fojut R. New injury trends emerge during COVID-19 pandemic. Trauma Systems News, 2020. https://www.trauma-news.com/2020/07/new-injury-trends-emerge-duringcovid-19-pandemic/ (8 Oct 2020).

16 CenturaHealth. Our Emergency Departments are Ready to Care for You. 2020. https:// www.youtube.com/watch?v=1 crD58Relxw\&feature=emb_logo (8 Oct 2020).

17 Research Medical Center. Enhanced safety protections: An update for our patients. https://researchmedicalcenter.com/covid-19/latest-updates/enhanced-safetyprotections.dot (8 Oct 2020)

18 Bates J. "We're Catching It Double." Amid Coronavirus Lockdowns, Gun Violence Continues to Plague Chicago. TIME Mag. 2020. https://time.com/5818553/gunviolence-chicago-coronavirus (8 Oct 2020).

19 Hatchimonji JS, Swendiman RA, Seamon MJ, Nance ML. Trauma does not quarantine: violence during the COVID-19 pandemic. Ann Surg 2020:272:e53-4.

20 Bruce G. Despite Pandemic, Trauma Centers See No End to 'The Visible Virus of Violence'. Kaiser Health News. 2020. https://khn.org/news/despite-pandemic-traumacenters-see-no-end-to-the-visible-virus-of-violence (8 Oct 2020).

21 American College of Surgeons Committee on Trauma. Maintaining Trauma Center Access \& Care during the COVID-19 Pandemic: Guidance Document for Trauma Medical Directors. 2020. https://www.facs.org/quality-programs/trauma/maintainingaccess (8 Oct 2020).

22 Zhou F, Yu T, Du R, Fan G, Liu Y, Liu Z, Xiang J, Wang Y, Song B, Gu X, et al. Clinical course and risk factors for mortality of adult inpatients with COVID-19 in Wuhan, China: a retrospective cohort study. Lancet 2020;395:1054-62.

23 Centers for Disease Control and Prevention (CDC). Coronavirus Disease 2019 (COVID-19): Older Adults. 2020. https://www.cdc.gov/coronavirus/2019-ncov/needextra-precautions/older-adults.html\#: :text=In\%20general\%2C\%20your\%20risk\% 20of,aged\%2065\%20years\%20and\%20older (19 Oct 2020).

24 Span P. You're a Senior. How Do You Calculate Coronavirus Risk Right Now? The New York Times. 2020. https://www.nytimes.com/2020/07/17/health/seniors-coronavirusreopenings.html (19 Oct 2020)

25 Schmidt S, Natanson $\mathrm{H}$. With kids stuck at home, ER doctors see more severe cases of child abuse. Washington Post. 2020. https://www.washingtonpost.com/education/ 2020/04/30/child-abuse-reports-coronavirus (8 Oct 2020). 